
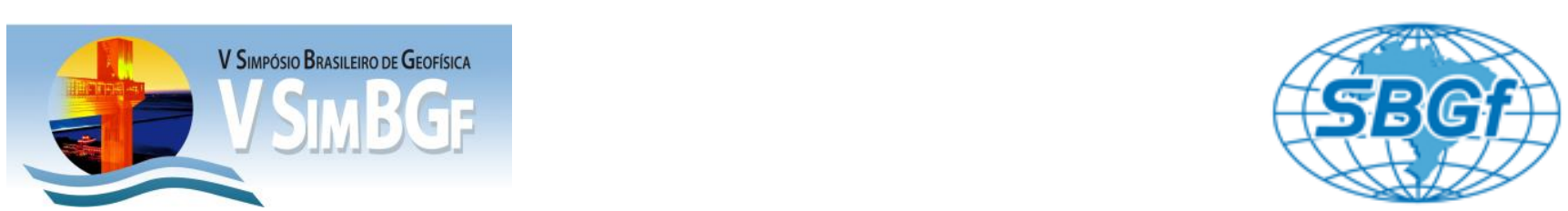

\title{
Método de inversão mineralógica a partir de perfis geofísicos de um poço do Campo de Namorado, Bacia de Campos
}

Yan Araujo Borges ${ }^{1}$ e Jorge Leonardo Martins ${ }^{2}$

${ }^{1}$ Universidade Federal Fluminense e ${ }^{2}$ Observatório Nacional

Copyright 2012, SBGf - Sociedade Brasileira de Geofísica

Este texto foi preparado para a apresentação no V Simpósio Brasileiro de Geofísica, Salvador, 27 a 29 de novembro de 2012. Seu conteúdo foi revisado pelo Comitê Técnico do V SimBGf, mas não necessariamente representa a opinião da SBGf ou de seus associados. É proibida a reprodução total ou parcial deste material para propósitos comerciais sem prévia autorização da SBGf.

\section{Abstract}

In the development phase of an oil and gas reservoir, petrophysical characterization of sedimentary formations that compose the reservoirs assists many professionals in the important task of maximizing the production of hydrocarbons. The ultimate goal is to minimize costs of production operations. In this context, the records obtained with the tools of geophysical well logging are used for the assessment of geological formations. In this project, we discuss a methodology to estimate the mineral composition of sedimentary formations from geophysical well logs. We will apply this methodology to the upper part of the Macaé Formation, in which the Namorado reservoir is inserted, located in the Campos Basin, northern coast of Rio de Janeiro State and the southern coast of Espirito Santo State (Bacoccoli et al. , 1980). We will use some of the geophysical well logs from the data set "Campo Escola Namorado", given by ANP to education and research institutes. In addition to the geophysical logs, we will also use the descriptions of facies of core samples extracted from the boreholes, conducted by Petrobras, also contained in the data set "Campo Escola Namorado". These are essential for evaluation of the formations being investigated, since the inversion algorithm for estimating the mineralogical composition requires the definition of the major lithological constituents, which may be made from these descriptions.

\section{Introdução}

A perfilagem geofísica de poços, segundo Nery (1990), torna possível a identificação das rochas da formação geológica a partir de suas propriedades elétricas, acústicas, radioativas, etc. A perfilagem, executada durante a perfuração, permite a avaliação das formações no que diz respeito à porosidade, permeabilidade, conteúdo de hidrocarbonetos, litologia, entre outros.

Desta maneira, é possível observar que este método geofísico é de suma importância na ultima fase de prospecção, fornecendo dados para geofísicos, geólogos, engenheiros de perfuração, engenheiros de reservatório, engenheiros de produção, etc. Cada um destes profissionais extrai dos perfis geofísicos informações de acordo com sua área de interesse. Geofísicos e geólogos, de um modo geral, procuram traçar correlações estratigráficas com a sísmica de reflexão, checando se

topos e bases das principais fácies sedimentares estão de acordo. Além disso, eles são responsáveis por determinar se o ambiente é adequado para formação de hidrocarbonetos, se há evidencias deste recurso, de que tipo ele é, e se está disponível em quantidades comerciais (Schlumberger, 1996).

A respeito das diversas variáveis que afetam as medidas das ferramentas de perfilagem, evidenciamos a composição mineralógica e, por consequência, a litologia das formações. A partir destas informações é possível caracterizar o reservatório sob diversos aspectos.

Propomos neste trabalho uma metodologia para que seja feita uma Inversão Mineralógica a partir de dados de perfis de um poço do Campo de Namorado, na Bacia de Campos. Com o auxilio de testemunhos retirados do poço no mesmo intervalo, faremos suposições a respeito do conteúdo mineralógico, coletaremos as propriedades geofísicas de cada constituinte, elaboraremos um modelo de rocha sedimentar para as imediações do poço e executaremos um script computacional que calculará o percentual volumétrico de cada constituinte da formação em questão.

O objetivo deste projeto é verificar a eficácia de nossa metodologia, fazendo a análise da mineralogia calculada e identificando intervalos coerentes com o que foi interpretado através dos testemunhos. Assim, poderemos definir se o método é adequado para a estimativa da composição mineralógica dos intervalos não testemunhados deste campo petrolífero.

\section{Área de Estudo}

A Bacia de Campos fica localizada na região sudeste do Brasil, abrangendo áreas do litoral norte do Estado do Rio de Janeiro e do litoral sul do Estado do Espirito Santo. A bacia é limitada ao sul pelo Arco de Cabo Frio e ao norte pelo Arco de Vitória.

$\mathrm{Na}$ estratigrafia da bacia, uma megassequência de deposição marinha pós-rifte e drifte formou o que Schaller (1982) definiu como Formação Macaé. Esta formação é caracterizada por carbonatos de aguas rasas (calcirruditos, calcarenitos, calcisiltitos e calcilutitos) de idade Albiana em sua parte inferior e por sedimentos clásticos/químicos (arenitos, conglomerados, folhelhos, diamictitios e margas) de idade Albiana e Cenomaniana em sua parte superior, estes representando o ápice da transgressão marinha (Barboza, 2005) (Figura 2.2). Segundo Bacoccoli et al. (1980), nesta parte superior, diretamente acima dos carbonatos, encontra-se 0 Reservatório Namorado, foco principal de estudo neste projeto. 
O Campo de Namorado foi descoberto em 1975 através do poço 1-RJS-19, em lamina d'agua de 166m (Barboza et al., 2004), a $80 \mathrm{~km}$ da costa (Figura 1). O reservatório é composto por arenitos turbidíticos de idade Albiana Superior a Cenomaniano Médio/Superior, e foi a primeira descoberta de acumulação de hidrocarbonetos encontrada neste tipo de rocha. Os limites do reservatório encontram-se entre 2900 e 3400 metros de profundidade, tendo o óleo sido encontrado entre 2980 e 3080m (Barboza et al., 2004).

É comum encontrar na literatura a menção ao Reservatório Namorado como Arenito Namorado, denominado desta maneira pela Petrobras por se tratar de um reservatório pioneiro de arenitos turbidíticos arcoseanos (ricos em feldspatos potássicos)

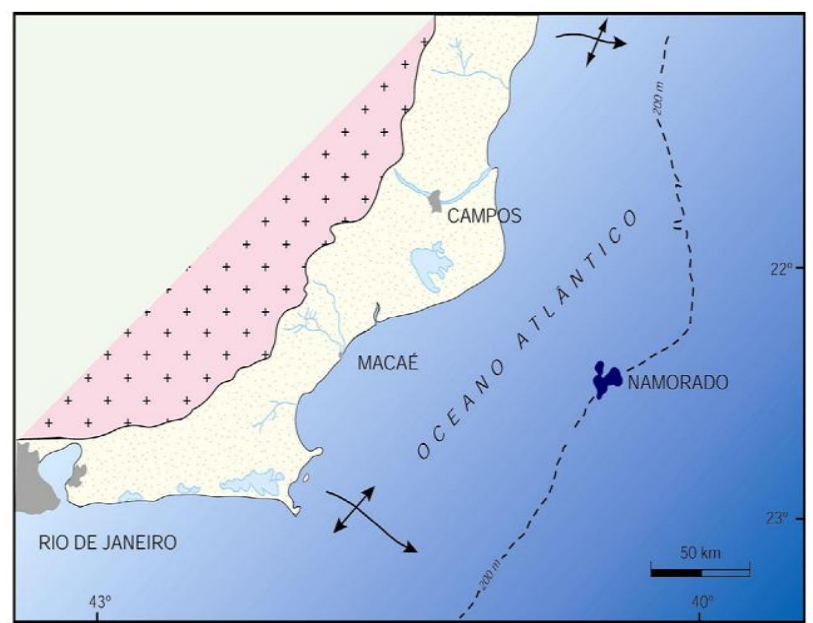

Figura 1 - Localização do Campo de Namorado. As setas indicam os limites da Bacia de Campos. Fonte: Barboza et al., 2004.

\section{Metodologia}

Faremos uso dos seguintes perfis geofísicos do poço NA04 (Figura 2): Sônico $(\Delta t)$, Raios Gama Naturais ( $G R$ ), Porosidade Neutrônica $\left(\phi_{n}\right)$ e Densidade $\left(\rho_{b}\right)$. O registro das ferramentas foi feito entre 2950 e 3150m de profundidade. Com o intuito de facilitar a visualização destes dados, os valores foram plotados (Figura 3).

Juntamente com os dados das ferramentas geofísicas de poço, temos as análises sequenciais de testemunhos retirados neste mesmo intervalo de dados (Figura 4). Os testemunhos são fundamentais não só neste trabalho, mas como em qualquer outro que envolva o estudo de reservatórios. Suas informações são precisas e detalhadas e é a partir dos testemunhos que podemos fazer um bom uso da perfilagem geofísica de poço, correlacionando as fácies sedimentares e até calibrando as ferramentas com base nos testemunhos para que uma melhor interpretação seja feita.

A análise dos testemunhos e a confecção das colunas litológicas para os poços que iremos trabalhar foram realizadas pela Petrobras entre os anos de 1993 e 2000 (Tabela 1). A partir destes dados foi possível definir os principais constituintes das fácies, e elaborar o modelo de rocha que será essencial para nossa metodologia, como veremos mais adiante.

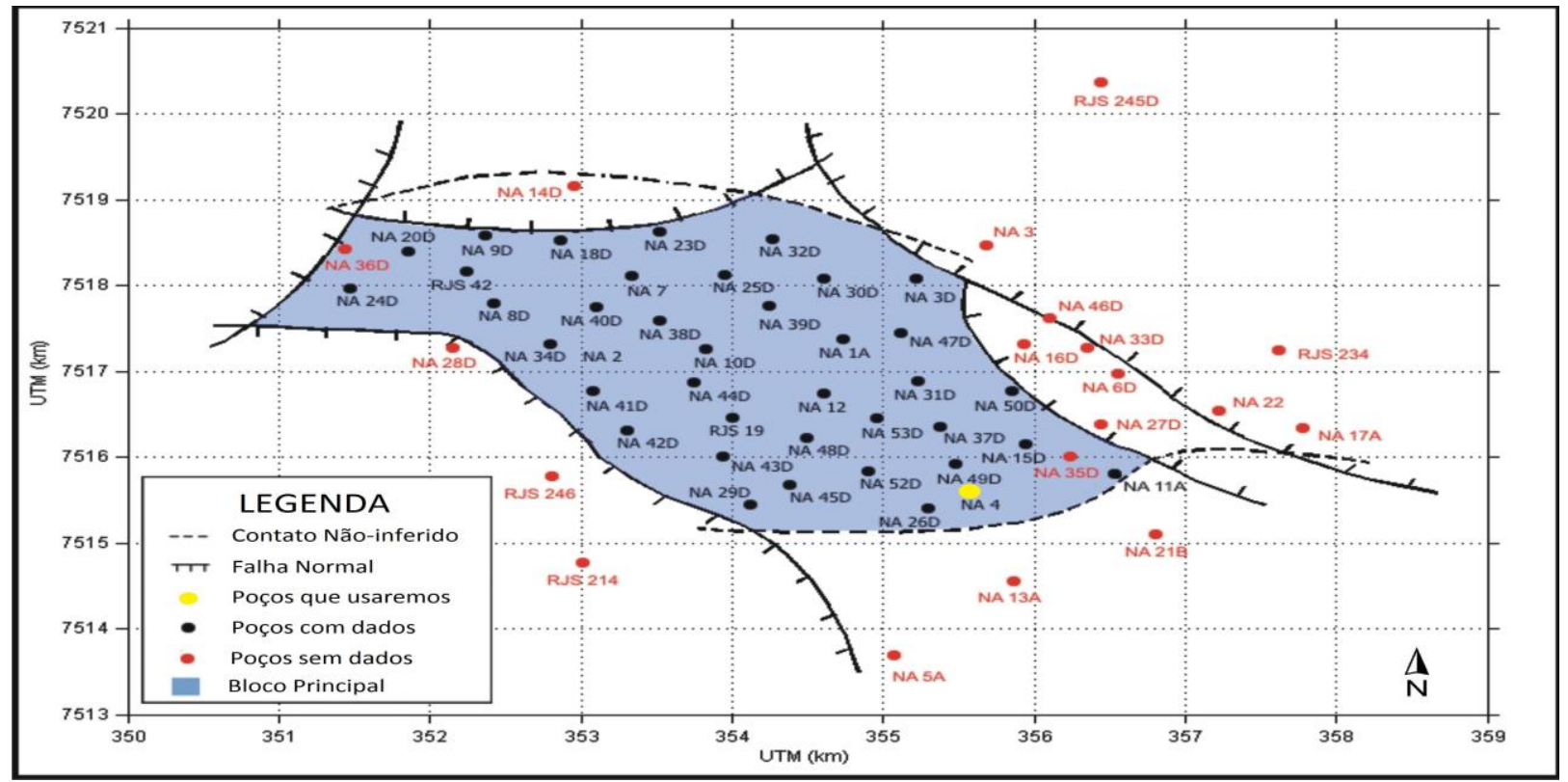

Figura 2 - Mapa Estrutural do Campo de Namorado. Poço NA04, que será usado no trabalho, marcado em amarelo. 


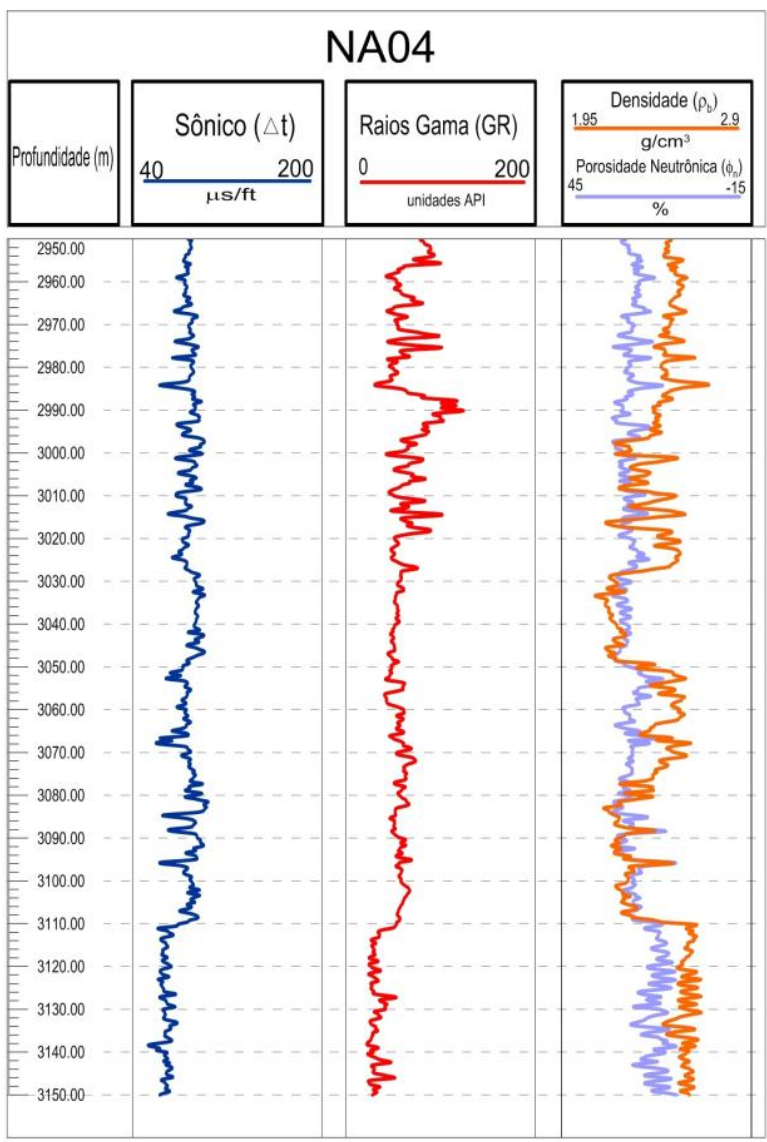

Figura 3 - Perfis Geofísicos do poço NA04.

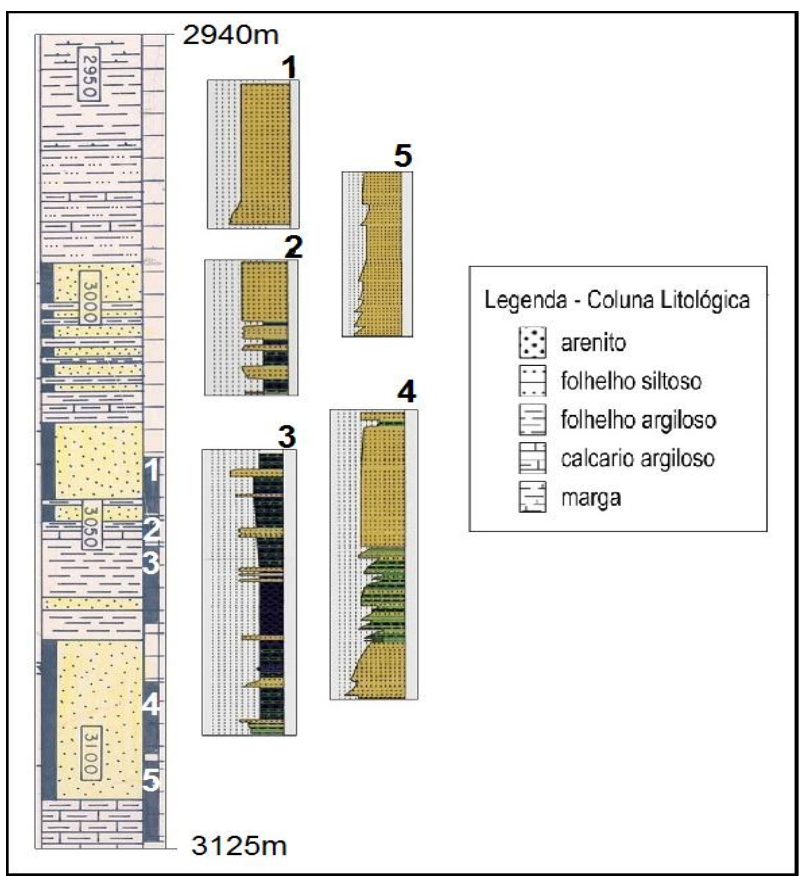

Figura 4 - Coluna Litológica e Testemunhos do poço NA04.
Tabela 1 - Descrições e constituintes principais das fácies dos testemunhos do poço NAO4.

\begin{tabular}{|c|c|c|c|}
\hline Testemunho & $\begin{array}{l}\text { Intervalo de } \\
\text { Profundiddade } \\
\text { (m) }\end{array}$ & Descrição das Fácies & $\begin{array}{l}\text { Consitituintes } \\
\text { Principals }\end{array}$ \\
\hline 1 & $\begin{array}{l}3036,5- \\
3042,8\end{array}$ & Arenito arcoseano bem selecionado & Quartzo, feldspato \\
\hline 2 & $3048,0-3053,9$ & $\begin{array}{c}\text { Arenito arcoseano bem selecionado } \\
\text { (topo); Interlaminado de siltito argilloso } \\
\text { (base) }\end{array}$ & $\begin{array}{l}\text { Quartzo, } \\
\text { feldspato, } \\
\text { argilominerais }\end{array}$ \\
\hline 3 & $3055.5-3072.7$ & 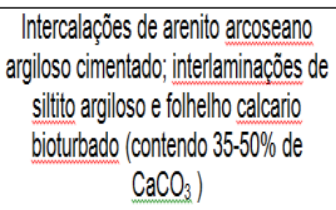 & $\begin{array}{l}\text { Quartzo, } \\
\text { feldspato, calcita, } \\
\text { argilominerais }\end{array}$ \\
\hline 4 & $3086.5-3100.8$ & $\begin{array}{l}\text { Arenito arcoseano bem selecionado } \\
\text { cimentado; intercalaçóes de folheho }\end{array}$ & $\begin{array}{l}\text { Quartzo, } \\
\text { feldspato, } \\
\text { argilominerais }\end{array}$ \\
\hline 5 & $3103.5-3119.5$ & $\begin{array}{l}\text { Arenito arcoseano bem selecionado } \\
\text { cimentado (topo); Interlaminacoues } \\
\text { ritmicas de calcilutito, margae } \\
\text { folhelho; conglomerado e brechas } \\
\text { carbonáticas (base) }\end{array}$ & $\begin{array}{l}\text { Quartzo, } \\
\text { feldspato, calcita, } \\
\text { argilominerais }\end{array}$ \\
\hline
\end{tabular}

Com a definição dos principais constituintes minerais das formações sedimentares da área de estudo respaldada na descrição de fácies analisadas nos testemunhos, elaboramos um modelo conceitual para todas as rochas que compõem a parede do poço (Figura 5).

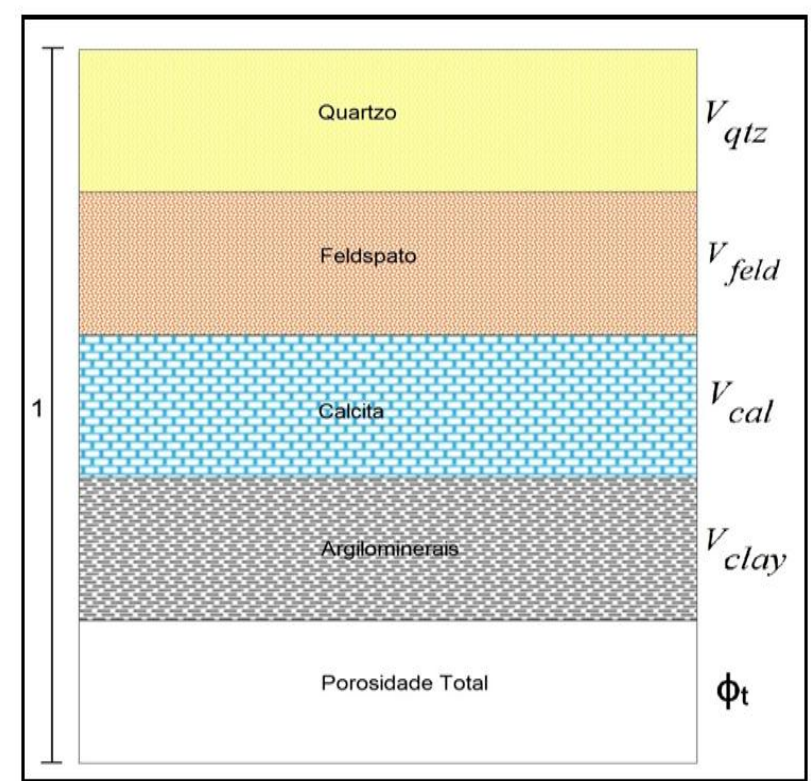

Figura 5 - Modelo conceitual de Rocha. Modificado de Schön (1996) e Borges \& Martins (2011). 
Os volumes de quartzo $\left(\mathrm{V}_{\mathrm{qtz}}\right)$, feldspato $\left(\mathrm{V}_{\text {feld }}\right)$, calcita $\left(\mathrm{V}_{\text {cal }}\right)$ e argilominerais $\left(V_{\text {clay }}\right)$ constituem a Matriz rochosa, ou seja, são os elementos sólidos da rocha (arcabouço, matriz e cimento). Complementando volumetricamente a formação, temos a porosidade total $(\phi t)$, que representa a parte da rocha que pode ser preenchida por fluidos.

Considerando que a totalidade dos poros esteja $100 \%$ saturada por fluidos (seja lama de perfuração, gás, óleo ou uma mistura de dois ou mais destes), define-se então um novo componente, o volume de fluido $\left(\mathrm{V}_{\mathrm{f}}\right)$. Logo, teremos a seguinte equação:

$V_{q t z}+V_{\text {feld }}+V_{\text {cal }}+V_{\text {clay }}+V_{f}=1$

(Equação 1)

Fazendo uso da Lei das Misturas que diz que "em um sistema multicomposto cada componente contribui volumetricamente para as propriedades da mistura na razão da fração volumétrica de um dos componentes vezes a propriedade deste" (Nery, 1990) e considerando a linearidade das propriedades, as respostas de cada ferramenta de perfilagem para cada profundidade $\underline{\mathrm{i}}$ ( $\rho_{b_{i}}$, $\left.\phi_{n_{i}}, G R_{i}, \Delta t_{i}\right)$ serão resultado do somatório dos volumes de cada constituinte de nosso modelo rochoso $\left(V_{\text {qtz }}, V_{\text {feld }}, V_{\text {cal }}, V_{\text {clay }}, V_{f}\right)$ vezes seus respectivos valores da propriedade que está sendo medida $\left(\rho_{\text {qtz }}, \rho_{\text {feld }}, \rho_{\text {cal }} \rho_{\text {clay }}, \rho_{f} ; \phi_{n_{\text {qtz }}}, \phi_{n_{\text {feld }}}, \phi_{n_{\text {cal }}}, \phi_{n_{\text {clay }}}, \phi_{n_{f}} ; G R_{q t z}\right.$,

$\left.G R_{\text {feld }}, G R_{\text {cal }}, G R_{\text {clay }}, G R_{f} ; \Delta t_{\text {qtz }}, \Delta t_{\text {feld }}, \Delta t_{\text {cal }}, \Delta t_{\text {clay }}, \Delta t_{f}\right)$.

Organizando as equações juntamente com a equação 1 , teremos:

$$
\begin{aligned}
& \rho_{b_{i}}=V_{\text {gtz }} \cdot \rho_{\text {glz }}+V_{\text {feld }} \cdot \rho_{\text {feld }}+V_{\text {cal }} \cdot \rho_{\text {cal }}+V_{\text {clay }} \cdot \rho_{\text {clay }}+V_{f} \cdot \rho_{f} \\
& \phi_{n_{i}}=V_{q t z} \cdot \phi_{n_{\text {qlz }}}+V_{\text {feld }} \cdot \phi_{n_{\text {fedd }}}+V_{\text {cal }} \cdot \phi_{n_{\text {cal }}}+V_{\text {clay }} \cdot \phi_{n_{\text {dag }}}+V_{f} \cdot \phi_{n_{f}} \\
& G R_{i}=V_{\text {qtz }} \cdot G R_{\text {qtz }}+V_{\text {feld }} \cdot G R_{\text {feld }}+V_{\text {cal }} \cdot G R_{\text {cal }}+V_{\text {clay }} \cdot G R_{\text {clay }}+V_{f} \cdot G R_{f} \quad \text { (Equação 2) } \\
& \Delta t_{i}=V_{q t z} \cdot \Delta t_{\text {gtz }}+V_{\text {feld }} \cdot \Delta t_{\text {feld }}+V_{\text {cal }} \cdot \Delta t_{\text {cal }}+V_{\text {clay }} \cdot \Delta t_{\text {clay }}+V_{f} \cdot \Delta t_{f} \\
& 1=V_{\text {grt }}+V_{\text {feld }}+V_{\text {cal }}+V_{\text {clay }}+V_{f}
\end{aligned}
$$

Definidas as equações, podemos perceber que se trata de um sistema linear de cinco equações e cinco incógnitas $\left(V_{\text {qtz }}, V_{\text {feld }}, V_{\text {cal }}, V_{\text {clay }}, V_{f}\right)$ que ficaria da seguinte maneira na forma matricial:

$$
\left(\begin{array}{ccccc}
\rho_{q t z} & \rho_{\text {feld }} & \rho_{\text {cal }} & \rho_{\text {clay }} & \rho_{f} \\
\phi_{n_{q t z}} & \phi_{n_{\text {feld }}} & \phi_{n_{\text {cal }}} & \phi_{n_{\text {clay }}} & \phi_{n_{f}} \\
G R_{q t z} & G R_{\text {feld }} & G R_{c a l} & G R_{c l a y} & G R_{f} \\
\Delta t_{q t z} & \Delta t_{\text {feld }} & \Delta t_{c a l} & \Delta t_{c l a y} & \Delta t_{f} \\
1 & 1 & 1 & 1 & 1
\end{array}\right) \times\left(\begin{array}{c}
V_{q t z} \\
V_{f e l d} \\
V_{c a l} \\
V_{c l a y} \\
V_{f}
\end{array}\right)=\left(\begin{array}{c}
\rho_{b_{i}} \\
\phi_{n_{i}} \\
G R_{i} \\
\Delta t_{i} \\
1
\end{array}\right)
$$

(Equação 3)

Os valores médios das propriedades de cada constituinte $\left(\rho_{\text {qtz }}, \rho_{\text {feld }}, \rho_{\text {cal }} \rho_{\text {clay }}, \rho_{f} ; \phi_{n_{\text {qtz }}}, \phi_{n_{\text {feld }}}, \phi_{n_{\text {cal }}}, \phi_{n_{\text {clay }}}, \phi_{n_{f}} ; G R_{q t z}\right.$,

$$
\left.G R_{\text {feld }}, G R_{\text {cal }}, G R_{\text {clay }}, G R_{f} ; \Delta t_{\text {qtz }}, \Delta t_{\text {feld }}, \Delta t_{\text {cal }}, \Delta t_{\text {clay }}, \Delta t_{f}\right)
$$

foram separadamente obtidos em laboratório pelas próprias ferramentas de perfilagem e estão demonstrados na Tabela 2.

Tabela 1 - Respostas médias de cada ferramenta para cada constituinte da formação retiradas de Schlumberger (2009), com exceção dos itens marcados com *.

\begin{tabular}{|c|c|c|c|c|}
\hline Constituinte da Rocha & $\rho$ & $\phi_{n}$ & $\begin{array}{c}\text { GR (unidades } \\
\text { API) }\end{array}$ & $\Delta t$ \\
$\left(\mathrm{~g} / \mathrm{cm}^{3}\right)$ & $(\mu \mathrm{s} / \mathrm{ft})$ \\
\hline Quartzo (qtz) & 2.64 & -1.00 & $1.00^{*}$ & 56.00 \\
\hline $\begin{array}{c}\text { Feldspato - Ortoclásio } \\
\text { (feld) }\end{array}$ & 2.52 & -2.00 & 220.00 & 69.00 \\
\hline $\begin{array}{c}\text { Calcita (cal) } \\
\text { Argilominerais - IIIita } \\
\text { (clay) }\end{array}$ & 2.52 & 20.00 & 250.00 & $86.00^{*}$ \\
\hline Fluido (f) & $1.10^{*}$ & $100.00^{*}$ & $0.00^{*}$ & $185.00^{*}$ \\
\hline
\end{tabular}

Como podemos ver na Tabela 2, é necessário explicar os motivos que nos levaram a adotar alguns valores (marcados com ${ }^{*}$ ), seja pela falta da definição destes na referência bibliográfica ou por empirismo.

A ferramenta responsável pela medição da densidade é capaz de detectar, geralmente, apenas a porção rochosa que está contaminada pela lama de perfuração (zona lavada). Este fluido, responsável pela lubrificação e pela manutenção da pressão, são misturas de águas pura e salgada ( $\mathrm{NaCl}$ dissolvido) que tem densidades entre $1.0 \mathrm{~g} / \mathrm{cm}^{3}$ e $1.10 \mathrm{~g} / \mathrm{cm}^{3}$ (Glover, 2000). Por considerarmos mais provável o uso de uma solução aquosa salgada (com maior densidade) do que o uso de água pura, usamos o valor de $1.10 \mathrm{~g} / \mathrm{cm}^{3}\left(\rho_{f}\right)$ para o fluido que preenche os poros rochosos.

Como o tipo de fluido definido possui alto índice de Hidrogênio, consideramos também que a resposta da ferramenta de perfilagem neutrônica teria sua resposta máxima neste constituinte, ou seja, $100.00 \%$. A ferramenta de Raios Gama Naturais mede a radiação emitida por isótopos de Potássio, Tório e Urânio, assim, o fluido que definimos não influenciaria neste perfil, obtendo resposta mínima, $0.00 \mathrm{API}$. Da mesma forma, o quartzo e a calcita também não teriam influência neste perfil. Então, com o único intuito de diferenciá-los do fluido, atribuímos os valores de 1.00 API para estes dois minerais.

A respeito do valor de $\Delta t$ do fluido, Schlumberger (2009) define que a água pura possui um valor de $208 \mu \mathrm{s} / \mathrm{ft}$ (microsegundos por pé), enquanto que uma solução 
aquosa contendo $20 \%$ de $\mathrm{NaCl}$ teria $181.8 \mu \mathrm{s} / \mathrm{ft}$ e outra contendo $10 \%$ de $\mathrm{NaCl}$ teria $192.3 \mu \mathrm{s} / \mathrm{ft}$. Ao mesmo tempo, Schön (1996), define que a solução de $20 \%$ de $\mathrm{NaCl}$ teria densidade de $1.146 \mathrm{~g} / \mathrm{cm}^{3}$ e a de $10 \%$ teria 1.073 . Assim, com base nestes dados, adotamos o valor de $185 \mu \mathrm{s} / \mathrm{ft}$ empiricamente para $0 \Delta t$ de um fluido com $\rho$ igual a $1.10 \mathrm{~g} / \mathrm{cm}^{3}$.

Novamente, na publicação de Schlumberger (2009) não há citação do valor de tempo de trânsito $(\Delta t)$ para nenhum mineral de argila, inclusive para a illita, apesar de este ser o argilomineral com o maior número de informações. Porém, segundo Nery (1990), os argilominerais afetam o perfil sônico aumentando o tempo de trânsito onde estão presentes. Isto se deve ao acúmulo de água intersticial nas rochas com alto teor de argila, como folhelhos e margas. A partir desta informação, coletamos valores médios do perfil sônico para intervalos com rochas argilosas presentes (tendo os testemunhos como referência) e de forma empírica definimos o valor de $86 \mu \mathrm{s} / \mathrm{ft}$.

Com as considerações supracitadas, os valores da tabela são então inseridos na equação 4 . Teremos a seguinte expressão:

$$
\left(\begin{array}{ccccc}
2.64 & 2.52 & 2.71 & 2.52 & 1.10 \\
-1.00 & -2.00 & 0.20 & 20.00 & 100.00 \\
1.00 & 220.00 & 1.00 & 250.00 & 0.00 \\
56.00 & 69.00 & 49.00 & 86.00 & 185.00 \\
1 & 1 & 1 & 1 & 1
\end{array}\right) \times\left(\begin{array}{c}
V_{q t z} \\
V_{\text {feld }} \\
V_{c a l} \\
V_{c l a y} \\
V_{f}
\end{array}\right)=\left(\begin{array}{c}
\rho_{b_{i}} \\
\phi_{n_{i}} \\
G R_{i} \\
\Delta t_{i} \\
1
\end{array}\right)
$$

(Equação 4)

Podemos ver que a equação 4 é do tipo:

$A \times X=Y$

(Equaçã r

Logo,

$X=A^{-1} \times Y$

(Equação 6)

$O$ vetor $Y$ conterá as respostas das ferramentas, sendo substituído em cada profundidade i, que irá ser percorrida no intervalo entre 2950 e $3150 \mathrm{~m}$. Para obtermos o vetor $\mathrm{X}$, que armazenará os volumes percentuais de cada constituinte para as respectivas profundidades, elaboramos um script no software MatLab que executa o Método dos Mínimos Quadrados Não-negativos através da função Isqnonneg, que aplica a seguinte condição:

$$
\min _{X}\|A \cdot X-Y\|_{2}^{2} \text {, onde } X \geq 0
$$

(Equação 7)

\section{Resultados}

Ao fim dos cálculos e através de gráficos de profundidade versus volumes percentuais, podemos visualizar 0 percentual volumétrico individual de cada constituinte comparado aos perfis geofísicos (Figura 6). Assim podemos visualizar certos atributos coerentes com os perfis, como o volume de fluido proporcional ao perfil Sônico, as áreas de reservatório (ricas em quartzo e feldspato) identificadas pelo crossplot do perfil de Densidade com o perfil de Porosidade Neutrônica, assim como o teor de minerais argilas responsável pela curva do perfil de Raios Gama.

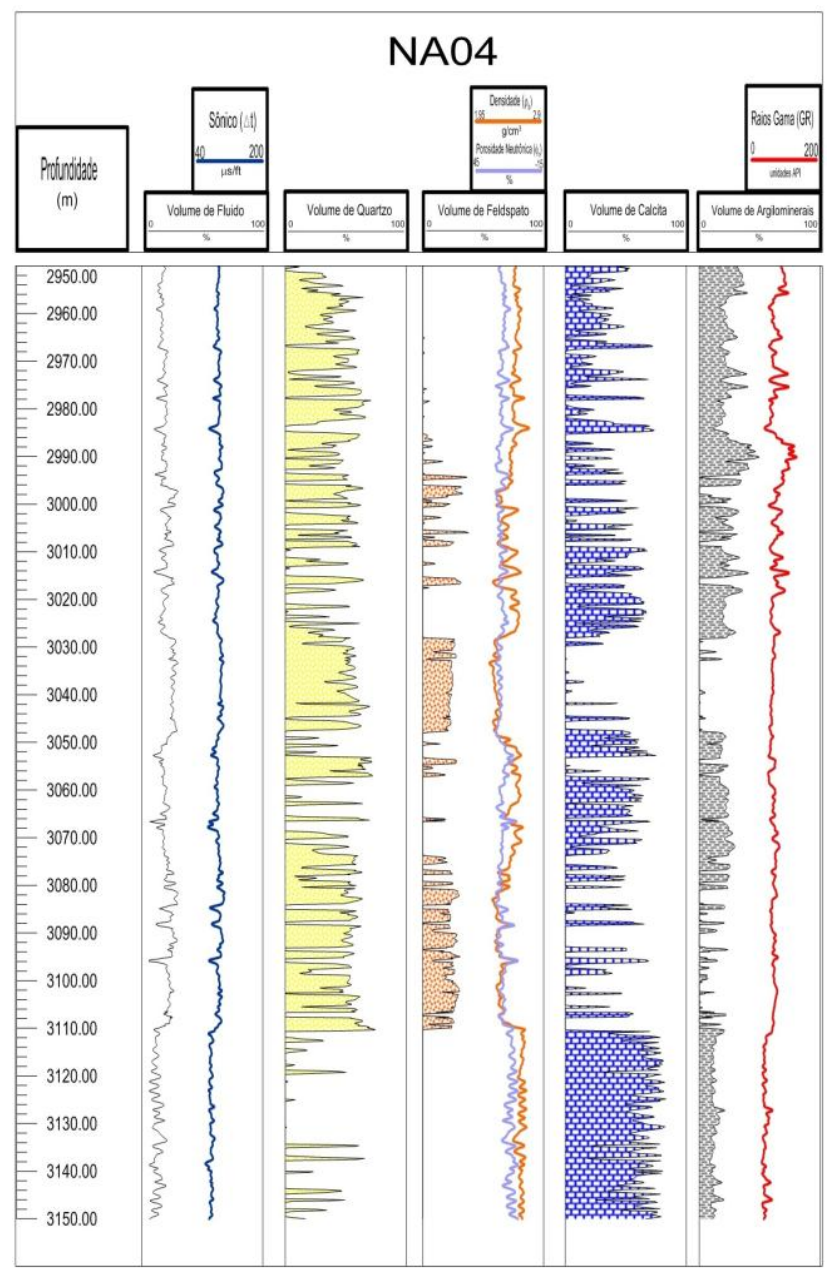

Figura 6 - Perfil de Percentual Volumétrico de cada constituinte e perfis geofísicos referentes ao poço NA04.

Além disso, na Figura 7 são mostrados os constituintes agregados (simbolizando a formação como um todo) comparados às colunas litológicas. Desta maneira, podemos comparar diretamente a interpretação realizada nos testemunhos e na coluna litológica e compara-la aos resultados de nossa metodologia, verificando se os constituintes estimados são coerentes com as fácies sedimentares identificadas. 


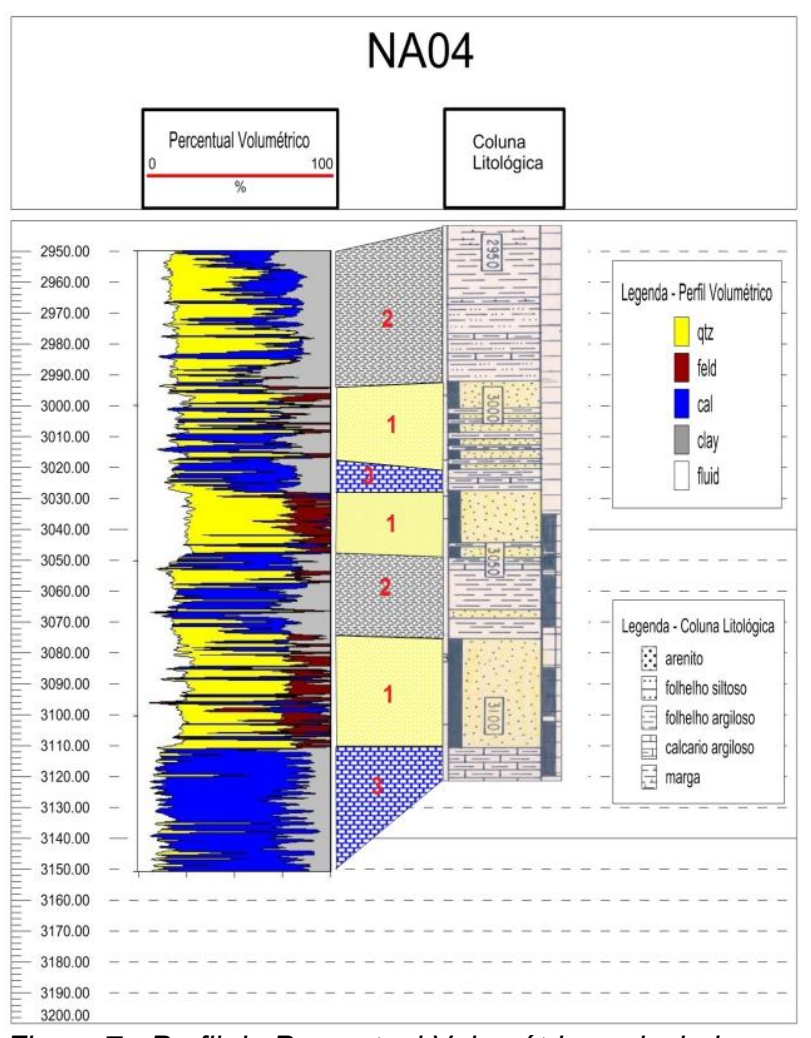

Figura 7 - Perfil de Percentual Volumétrico calculado e comparado à Coluna Litológica do poço NA04.

$\mathrm{Na}$ figura acima temos os intervalos de arenitos reservatórios marcados com o número 1 (ricos em quartzo, feldspato e fluido) e os de folhelho com o número 2 (ricos em argilominerais). Devemos destacar os dois intervalos de calcário (número 3), perfeitamente estimados pelo método aplicado, com altíssima porcentagem de calcita e argilominerais e pouco fluido detectado.

\section{Discussão e Conclusões}

Obviamente, as rochas que compõem a parede do poço não são só formadas por quartzo, feldspato, calcita, argilominerais e fluido. Elas são formadas também por componentes com propriedades físicas completamente diferentes em comparação com as que usamos neste projeto. Entretanto, ao analisar os testemunhos e pesquisando sobre geologia sedimentar, podemos dizer que não só as rochas presentes nesta área como qualquer outra em qualquer região do planeta teria, com certo nível de probabilidade, um ou mais destes quatro minerais em sua composição. Isto somado aos resultados obtidos com nosso método nos permite dizer que os constituintes que selecionamos são parâmetros razoáveis para o calculo da estimativa do percentual volumétrico.

Os minerais de argila têm uma particularidade em virtude de sua gênese, fazendo com que exista uma grande variedade destes minerais nas formações geológicas, cada um com diferentes propriedades físicas. Por isso, os valores utilizados para o cálculo de $\mathrm{V}_{\text {clay }}$ podem não terem sido os corretos, uma vez que a definição dos minerais argilosos que compõem efetivamente a formação é uma vertente da geologia bastante complexa e ampla. Porém, os resultados obtidos, mais uma vez, mostram que os valores que adotamos foram eficientes para caracterizar intervalos ricos em argilominerais.

Deve-se notar também que toda a extensão de dados que calculamos para todos os poços apresenta uma significativa porcentagem de volume de fluido, mesmo em sequencias sedimentares que não correspondem ao reservatório. Isto é resultado da influência da chamada "zona lavada", parte da parede dos poços que são contaminadas fortemente pelo fluido de perfuração, não indicando, desta maneira, a presença de hidrocarbonetos.

Com essas considerações finais, podemos dizer que o método de inversão mineralógica apresentado é bastante flexível, podendo ser adaptado para diferentes áreas, além de ser capaz de prover informações úteis para avaliar as formações sedimentares de um poço e estimar, com um bom nível de eficácia, a litologia dos intervalos não testemunhados.

\section{Referências}

Bacoccoli, G., Morales, R.G., Campos, O.A.J., 1990 The Namorado Oil Field: A Major Oil Discovery in the Campos Basin, Brazil. In: Giant Oil and Gas Fields of the Decade: 1968-1978. Tulsa: American Association of Petroleum Geologists, p. 329-338. (AAPG Memoir 30).

Barboza, E.G., 2005. Análise Estratigráfica do Campo de Namorado (Bacia de Campos) com base na Interpretação Sísmica Tridimensional. Tese de Doutorado, Curso de Pós-graduação em Geociências, UFRGS, 230 p.

Barboza , E. G., Tomazelli , L. J., Ayup-zouain, R. N., Rosa, M. L. C. C., 2004. Análise Faciológica e Modelo Deposicional do Arenito Namorado, Bacia de Campos, RJ. $3^{\circ}$ Congresso Brasileiro de P\&D em Petróleo e Gás, IBP, Salvador.

Borges, Y. A., Martins, J.L., 2011. Mineralogical Analysis for a Well in the Namorado Reservoir. 12th International Congress of the Brazilian Geophysical Society.

Glover, P., 2000. Chapter 13: The Formation Density Log. Petrophysics MSc Course Notes.

Nery, G. G., 1990. Perfilagem geofísica em poço aberto. Apostila do Curso de Engenharia de Petróleo, Centro de Ensino da PETROBRAS, Salvador, $231 \mathrm{p}$.

Schaller, H., 1982. Estratigrafia da Bacia de Campos. In: Congresso Brasileiro de Petróleo 2. Rio de Janeiro, 1982. Anais... Rio de Janeiro, IBP, trabalho nํㅜ 18..

Schlumberger, 1996 Introduction to Openhole Logging.

Schlumberger, 2009. Log Interpretation Chartbook.

Schön, J.H., 1996. Physical properties of rocks: Fundamentals and principles of petrophysics. Handbook of Geophysical Exploration, Seismic Exploration. Pergamon, Vol. 18, 583 p. 